\title{
ARGILOMINERAIS DO PALEOLAGO TREMEMBÉ E SISTEMAS DEPOSICIONAIS RELACIONADOS (PALEÓGENO, RIFT CONTINENTAL DO SUDESTE DO BRASIL)
}

\author{
CLÁUDIO RICCOMINI*, ARMANDO MÁRCIO COIMBRA*, LUCY GOMES SANT'ANNA**, \\ MAX BRANDT NETO**** \& JOSÉ VICENTE VALARELLI*
}

\begin{abstract}
CLAY MINERAIS OF THE TREMEMBÉ PALEOLAKE AND RELATED DEPOSITIONAL SYSTEMS (PALEOGENE, CONTINENTAL RIFT OF SOUTHEASTERN BRAZIL) Study of the clay mineral content of Oligocene lacustrine sediments of the Tremembé Formation and laterally correlative deposits of a marginal system of distal alluvial fans of the Resende Formation has furnished important indicators of paleoenvironmental and paleoclimatic conditions during the génesis of these minerais within the context of the Paleogene evolution of the Continental Rift of Southeastern Brazil. X-ray diffraction and scanning electron microscopy revealed clay minerais of the smectite and kaolinite groups and, to a much lesser extent, members of the mica and chlorite groups. Detrital clay minerais in the Tremembé and Resende Formations are mainly represented by smectites, generated under generally arid conditions probably during the Eocene. Ancient soils developed upon Precambrian basement rocks acted as remarkable source-areas for the smectites, although the conditions for their genesis are still unresolved. Eodiagenetic halloysite in deltaic sandstones of the Tremembé Formation was derived by decomposition of feldspar and is indicative of pluvial seasonality during sedimentation. Worm-like kaolinite was formed during a later diagenetic stage, without the influence of the depositional environment. The presence of kaolinite in the meandering fluvial system of the São Paulo Formation suggests a significam climatic change to humid conditions during the Late Oligocene. It appears, therefore, that the paleoclimatic and paleoenvironmental changes inferred from the clay mineralogy of the sediments studied here are in general accord with the pattern of global changes for the Paleogene as deduced from other geological and paleoceanographic evidence.
\end{abstract}

Key-Words: clay minerais, Tremembé Formation, paleolake, Cenozoic, Southeastern Brazil

RESUMO O emprego da difração de raios X e microscopia eletrônica de varredura no estudo dos argilominerais contidos nos sedimentos lacustres oligocênicos da Formação Tremembé e nos depósitos relacionados do sistema marginal de leques aluviais distais da Formação Resende, forneceu importantes indicações sobre as condições paleoambientais e paleoclimáticas para a gênese destes minerais, no contexto evolutivo das bacias do Rift Continental do Sudeste do Brasil durante o Paleógeno. Foram identificados argilominerais pertencentes aos grupos da esmectita e da caulinita, e subordinadamente da mica e clorita. Os argilominerais detríticos dos sedimentos das formações Tremembé e Resende são representados principalmente pelas esmectitas de bordos arqueados, sendo sua presença indicativa das condicões paleoclimáticas com tendência à aridez, vigentes durante a época de sua geração, provavelmente no Eoceno Inferior a Médio. As rochas pré-cambrianas do embasamento contribuíram em grande escala como área-fonte dos paleossolos esmectíticos, permanecendo ainda obscuros os processos genéticos envolvidos na formação destes argilominerais. Halloysitas eodiagenéticas, presentes nos arenitos deltaicos da Formação Tremembé, proviriam da decomposição de feldspatos e seriam indicativas de sazonalidade pluviométrica vigente à época da sedimentacão. Em estágios diagenéticos mais avançados e sem a influência do meio deposicional formaram-se caulinitas vermiformes. O sistema fluvial meandrante da Formação São Paulo, com sedimentos essencialmente cauliníticos, sugere uma significativa mudança climática para condições mais úmidas no Oligoceno Superior. De modo geral, as variações paleoclimáticas e paleoambientais indicadas pelos argilominerais dos sedimentos paleogênicos estudados mostram condições paleoambientais similares à tendência global.

Palavras-Chaves: argilominerais, Formação Tremembé, sistema lacustre, Cenozóico, Sudeste do Brasil

INTRODUÇ̃̃O A Formação Tremembé, originalmente definida por Almeida (1958), corresponde, na concepção atual (Riccomini 1989), a um sistema lacustre do tipo playa-lake, de idade oligocênica, desenvolvido na porção central da Bacia de Taubaté e, de forma mais restrita, na Bacia de São Paulo, ambas integrantes do Rift Continental do Sudeste do Brasil (RCSB) (Figs. 1, 2). O RCSB, anteriormente denominado de Sistema de Rifts da Serra do Mar (Almeida 1976), compreende ainda, de sudoeste para nordeste, a Bacia de Curitiba e o Graben de Guaraqueçaba, no Estado do Paraná, o Graben de Sete Barras e a Formação Pariqüera-Açu, no Estado de São Paulo, além das bacias de Resende, Volta Redonda, Graben de Casa de Pedra, Graben da Guanabara, Bacia de Itaboraí e Graben de Barra de São João, no Estado do Rio de Janeiro (Riccomini \& Coimbra 1992) (Fig. 1).

Riccomini (1989), baseado na análise de fácies e sistemas deposicionais, apresentou uma revisão litoestratigráfica dos depósitos das bacias de Taubaté, São Paulo, Resende e Volta
Redonda do RCSB, onde a Formação Tremembé está estratigraficamente situada na porção intermediária do Grupo Taubaté (Fig. 3), interdigitando-se, lateral e verticalmente, com os depósitos eocênicos da Formação Resende, esta representativa de um sistema de leques aluviais associados a planície aluvial de rios entrelaçados (braided). No topo do Grupo Taubaté comparece o sistema fluvial meandrante da Formação São Paulo, de idade oligocênica, cujos depósitos estão atualmente restritos à porção sudoeste da Bacia de Taubaté, estendendo-se a sudoeste para a Bacia de São Paulo, onde encontra-se melhor desenvolvido e, ainda com pequenas acumulações na Bacia de Resende. A passagem do sistema de leques aluviais da Formação Resende para o sistema fluvial meandrante da Formação São Paulo é transicional.

Na Bacia de Taubaté, o Grupo Taubaté é recoberto pelo sistema fluvial meandrante da Formação Pindamonhangaba (Riccomini 1989, Riccomini et al. 1991, Mancini 1995). Na Bacia de São Paulo tem-se o sistema fluvial entrelaçado da

Instituto de Geociências da Universidade de São Paulo (IG-USP) e Bolsista de Pesquisa do Conselho Nacional de Desenvolvimento Científico e Tecnológico (CNPq) - Caixa Postal 11.348, CEP 05422-970, São Paulo, SP, Brasil - FAX: 55-011-818.4129 - e-mail: riccomin@usp.br

Programa de Pós-Graduação em Mineralogia e Petrologia, Instituto de Geociências da Universidade de São Paulo (IG-USP) e Bolsista da Fundação de Amparo à Pesquisa do Estado de São Paulo (FAPESP) - e-mail: santann@usp.br

Instituto de Biociências, Letras e Ciências Exatas da Universidade Estadual Paulista "Júlio de Mesquita Filho" (IBILCE-UNESP), Campus de São José do Rio Preto, SP, Brasil 

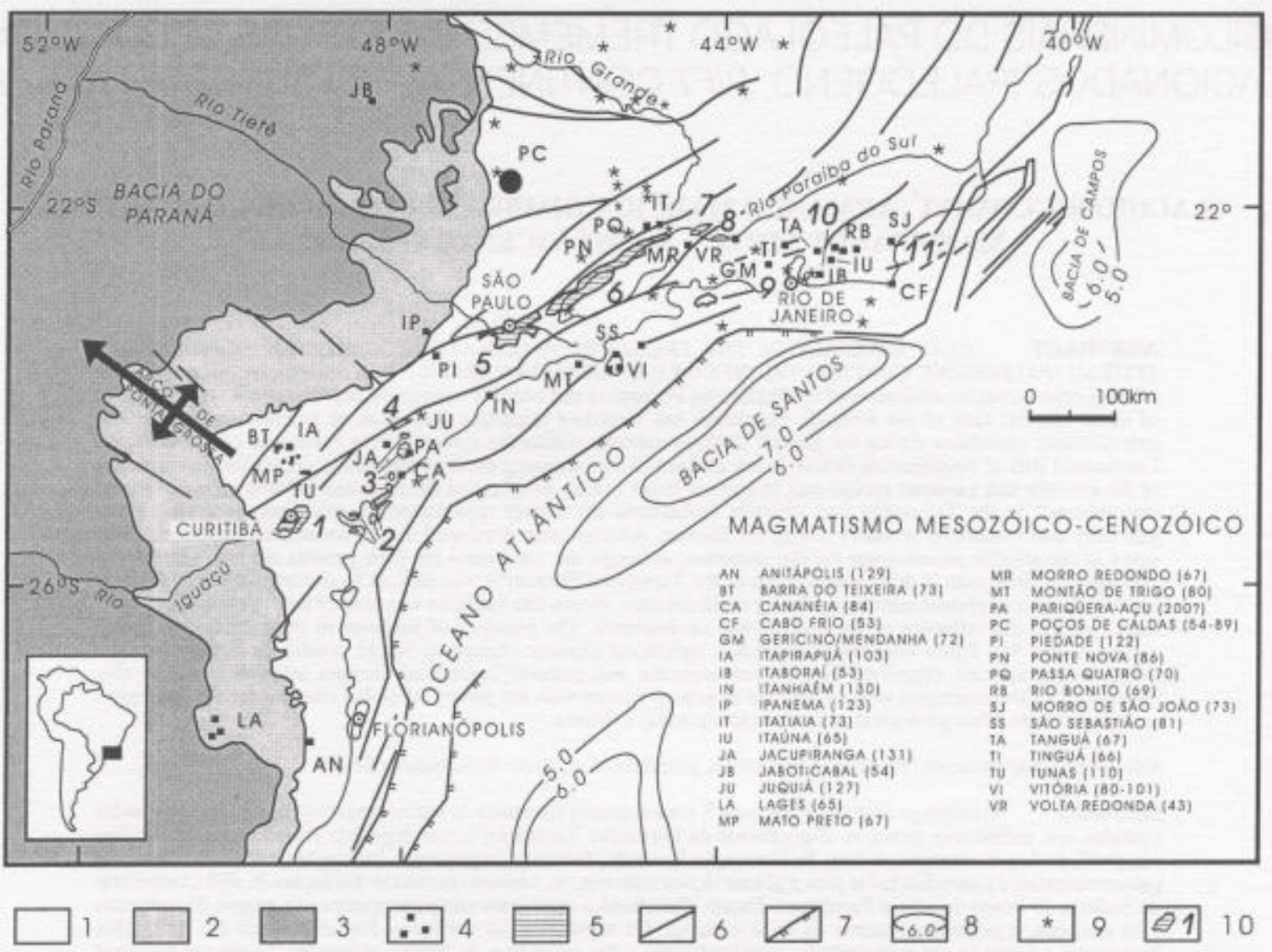

Figura 1 - Quadro geológico e tectônico regional do Rift Continental do Sudeste do Brasil-RCSB. Ilustração adaptada de Melo et al (1985), Riccomini (1989), Riccomini \& Coimbra (1992) e Riccomini (1995). 1) embasamento pré-cambriano; 2) sedimentos paleozóicos e mesozóicos da Bacia do Paraná; 3) rochas relacionadas ao vulcanismo da Formação Serra Geral, em parte recobertas por sedimentos e, nesses últimos, algumas intercalações de lavas alcalinas; 4) rochas relacionadas ao magmatismo MesozóicoCenozóico (ver quadro no interior da figura; idades entre parênteses); 5) sedimentos terciários do RCSB; 6) zonas de cisalhamento relacionadas ao Ciclo Brasiliano Pan-Africano, em parte reativadas pelo menos durante o Mesozóico e Cenozóico; 7) zonas de flexura; 8) isópacas, em quilometros, dos sedimentos das bacias costeiras; 9) epicentros de terremotos; 10) bacias do rift (1 - Bacia de Curitiba, 2 - Formação Alexandra e Graben de Guaraqueçaba, 3 - Formação Pariqüera-Açu, 4 - Graben de Sete Barras, 5 Bacia de São Paulo, 6 - Bacia de Taubaté, 7 - Bacia de Resende, 8 - Bacia de Volta Redonda, 9 - Graben da Guanabara, 10 - Bacia de Itaboraí, 11 - Graben de Barra de São João).

Figure 1 - Regional geologic-tectonic context of the Continental Rift of Southeastern Brazil (CRSB) (after Melo et al. 1985, Riccomini 1989, Riccomini \& Coimbra 1992 and Riccomini 1995). 1) Precambrian basement rocks; 2) Paleozoic and Mesozoic sediments of the Paraná Basin; 3) volcanic rocks of the Serra Geral Formation (Paraná Flood Volcanics); 4) Mesozoic-Cenozoic magmatic rocks (numbers in list at lowerright in Ma); 5) Tertiary sediments of the CRSB; 6) Brasiliano/Pan-African shear zones, in part reactivated during the Mesozoic-Cenozoic; 7) flexure zones; 8) isopachs, in km, of marginal offshore basins; 9) earthquake epicenter; 10) rift basins (1 - Curitiba Basin; 2 - Alexandra Formation and Guaraqueçaba Graben; 3 - Pariqüera-Açu Formation; 4 - Sete Barras Graben; 5 - São Paulo Basin; 6 Taubaté Basin; 7 - Resende Basin; 8 - Volta Redonda Basin; 9 - Guanabara Graben; 10 - Itaboraí Basin; 11 - Barra de São João Graben).

Formação Itaquaquecetuba, situado estratigraficamente acima do Grupo Taubaté, em contato direto com rochas do embasamento (Riccomini 1989).

Os sedimentos ora enfeixados na Formação Tremembé contêm argilominerais esmectíticos, com aproveitamento industrial, sendo seus principais depósitos explorados economicamente já há algumas décadas. No entanto, apesar de existirem referências à unidade há mais de um século, e do especial interesse nessas matérias-primas, os argilominerais da Formação Tremembé ainda não foram objeto de um estudo sistemático. As pesquisas realizadas até o momento são de caráter local e voltadas à caracterização tecnológica das argilas esmectíticas - frequentemente referidas como "bentoníticas" - da porção central da Bacia de Taubaté (e.g. Furia 1940, Couto 1953, Paiva Netto \& Nascimento 1956, Nicot \& Visconti 1959, IPT 1975, entre outros).

Suguio (1969) realizou o primeiro estudo de caráter eminentemente geológico e sedimentológico sobre os sedimentos da Bacia de Taubaté. Riccomini (1989) e Brandt Neto et al. (1991) avançaram no conhecimento da gênese dos argilominerais da bacia; mais recentemente, Riccomini et al. (1994) iniciaram a discussão das aplicações tecnológicas destas matérias-primas, com base nas características mineralógicas e genéticas dos minerais.

A presente contribuição expõe os resultados do estudo dos argilominerais contidos nos sedimentos lacustres oligocênicos da Formação Tremembé e nos depósitos do sistema marginal de leques aluviais distais da Formação Resende. São ainda discutidas as condições paleoambientais e paleoclimáticas propícias para a gênese destes minerais no contexto evolutivo das bacias do RCSB durante o Paleógeno.

CONTEXTO GEOLÓGICO DA BACIA DE TAUBATÉ Rochas do embasamento $O$ substrato pré-cenozóico do segmento do RCSB que encerra as bacias em análise compreende: terrenos proterozóicos do Cinturão de Dobra- 


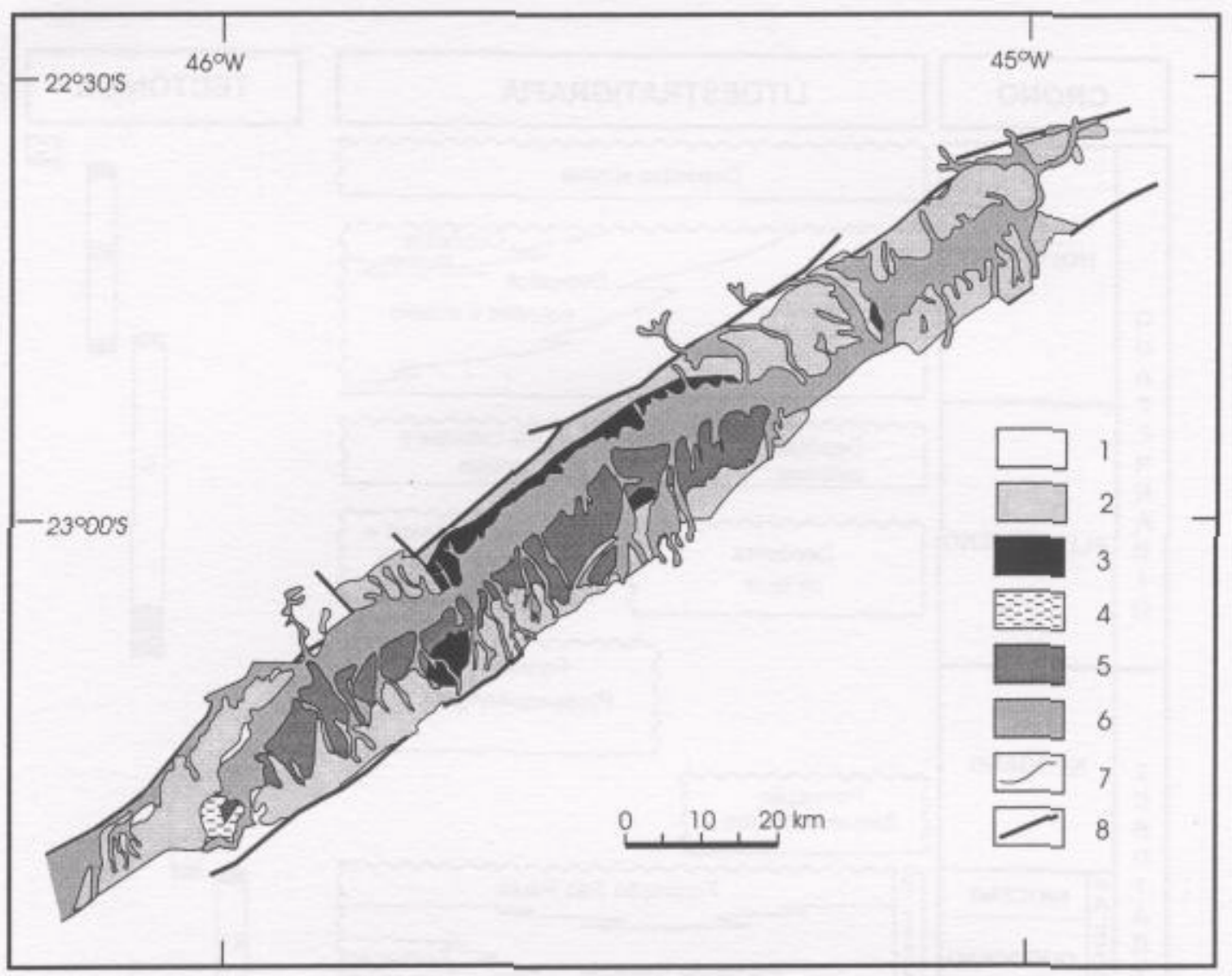

Figura 2 - Mapa geológico da Bacia de Taubaté, simplificado de Riccomini (1989). 1) rochas do embasamento; 2) Formação Resende; 3) Formação Tremembé; 4) Formação São Paulo; 5) Formação Pindamonhangaba; 6) sedimentos quaternários; 7) contatos litológicos; 8) falhas normais.

Figure 2 - Geologic map of Taubaté Basin (after Riccomini 1989). 1) basement rocks; 2) Resende Formation; 3) Tremembé Formation; 4) São Paulo Formation; 5) Pindamonhangaba Formation; 6) Quaternary sediments; 7) lithologic contacts; 8) normal faults.

mentos Ribeira (v.g. Hasui et al. 1975), constituídos por migmatitos com estruturas variadas, rochas metamórficas (milonito-gnaisses, gnaisses bandados, gnaisses graníticos, xistos, quartzitos e anfibolitos) e rochas ígneas (granitos e pegmatitos); intrusões de diabásio eocretáceas (Amaral et al 1967, Turner et al. 1995); rochas alcalinas cretáceo-terciárias dos grandes maciços de Passa Quatro, no extremo leste da Bacia de Taubaté, Itatiaia e Morro Redondo, nos arredores da Bacia de Resende, aos quais estão associados diques e soleiras (Riccomini 1989).

O preenchimento sedimentar paleogênico $O$ sistema de leques aluviais associados à planície aluvial de rios entrelaçados da Formação Resende ocupa as posições basal e lateral na Bacia de Taubaté, sendo seus depósitos os mais abundantes e expressivos da sedimentação paleogênica, compreendendo grande parte do pacote sedimentar. A Formação Resende apresenta três litofácies principais, com lamitos conglomeráticos, lamitos arenosos a argilosos, e arenitos, que marcam, respectivamente, a gradação entre as porções proximal, mediana e distal de um trato de sistema de leques aluviais, originados a partir de fluxos de massa nas bordas tectonicamente ativas das bacias (Riccomini 1989).

As rochas conglomeráticas da fácies proximal contêm seixos, calhaus e matacões, angulosos a subarredondados, de diversos tipos rochosos do embasamento, matriz argilosa a arenosa esverdeada, gradação normal e inversa, e acunhamento dos pacotes rumo ao eixo deposicional da bacia. A porção mediana da Formação Resende constitui-se de lamitos seixosos a arenosos, de coloração esverdeada, lateralmente interdigitados com os depósitos proximais. Os arenitos, repre- sentativos da sedimentação na planície aluvial, apresentam-se mal selecionados e com granulação média a grossa, podendo ser maciços, em pequenos corpos, ou com estratificações cruzadas acanaladas, constituindo extensos lençóis, os quais intercalam-se a lamitos argilosos. Sedimentos silto-arenosos, por vezes ricos em argila e com abundante matéria-orgânica, são relacionadas à deposição em pequenos lagos inter-lobos de leques aluviais coalescentes.

Na Formação Resende estão ainda presentes calcários calcíticos, na forma de crostas duras (calcretes), associados aos lamitos distais, e correspondem a horizontes pedogenéticos. Esses calcretes são conhecidos em outras bacias do RCSB, tendo sido inicialmente descritos por Tibana et al. (1984), associados aos depósitos terrígenos da Bacia de Itaboraí, posteriormente por Coimbra \& Riccomini (1985), nas bacias de Resende, Taubaté (Formação Resende) e Curitiba (Formação Guabirotuba) e, mais recentemente, por Riccomini \& Coimbra (1992) na Bacia de São Paulo. Em geral, estas crostas ocorrem como preenchimento de rachaduras de ressecação de espessura centimétrica nos lamitos argilosos, sob a forma nodular nos arenitos e lamitos arenosos, ou ainda como pacotes tabulares de espessura decimétrica (Riccomini 1989).

Lima \& Amador (1985) estudaram o conteúdo palinológico de uma camada de linhito da Formação Resende, na bacia homónima, e dataram a unidade do Eoceno Superior, ressaltando a possibilidade de ser mais antiga. A mesma idade foi também obtida para folhelhos da Formação Resende, presentes no Graben de Casa de Pedra, em Volta Redonda, RJ (Lima et al 1994). 


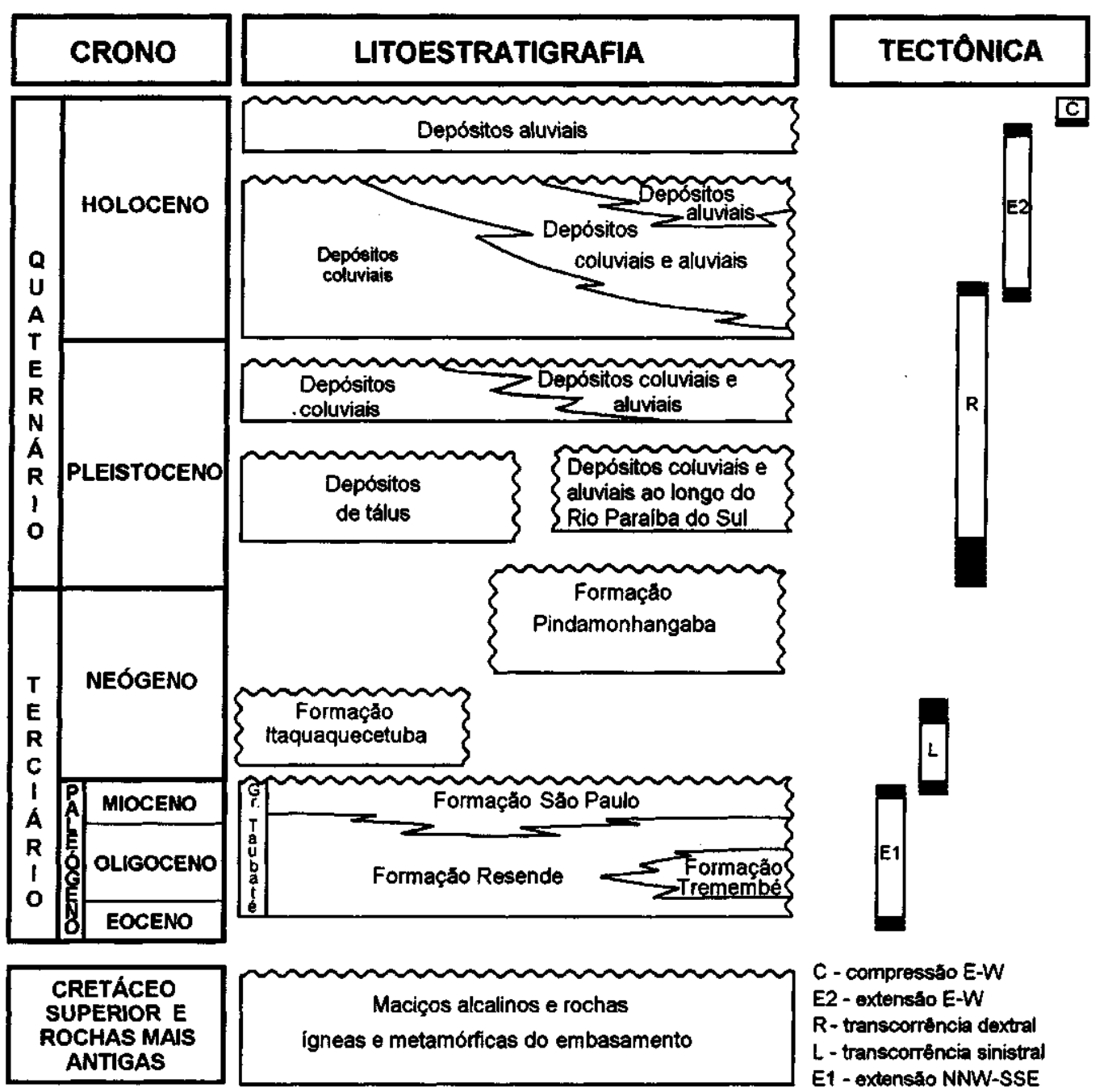

Figura 3 - Quadro litoestratigráfico e evolução tectono-sedimentar do RCSB. Ilustração adaptada de Riccomini (1989), Salvador (1994) e Mancini (1995).

Figure 3 - Lithostratigraphic chart and tectono-sedimentary evolution of the CRSB (after Riccomini 1989, Salvador 1994, Mancini 1995).

Riccomini et al. (1983) descreveram derrames de lavas ankaramíticas intercalados aos lamitos da Formação Resende presentes no Graben de Casa de Pedra (RJ); datações K-Ar em rocha total permitiram situar estas lavas no Eoceno Superior (ca. $43 \mathrm{Ma}$ ). Lavas de natureza semelhante foram descritas por Klein \& Valença (1984), recobrindo os calcários paleogênicos da Bacia de Itaboraí, tendo sido datadas do Eoceno Inferior a Médio (ca. 53 Ma, Riccomini \& Rodrigues Francisco 1992).

O sistema de leques aluviais da Formação Resende apresenta gradação lateral e vertical para o sistema playa-lake da Formação Tremembé, no qual Riccomini (1989) reconheceu cinco litofácies principais:

a) fácies de argilitos verdes maciços, frequentemente fossilíferos (presença de moldes de ostracodes e restos de aves) e, localizadamente, com gretas de contração e concreções carbonáticas de dimensões até decimétricas;

b) fácies de dolomitos com textura microesparítica, coloração verde acinzentada a branca, restrita à porção central da Bacia de Taubaté, onde ocorrem como camadas tabulares e contínuas, de espessuras decimétricas, intercaladas nos argilitos maciços; c) fácies de ritmitos formados pela alternância de lâminas ou camadas centimétricas de folhelhos e margas. Os folhelhos são de cor castanha a cinza escuro, laminados, localizadamente papiráceos, fossilíferos (presença de restos de peixes, coprólitos e impressões de plantas) e pirobetuminosos. As margas, por sua vez, são ricas em ostracodes;

d) fácies de arenitos com estratificação cruzada sigmoidal, granodecrescência ascendente de areia média, ocasionalmente areia grossa ou grânulos, até silte, forma de lobos, presença de laminações cavalgantes (climbing ripples), estando bem desenvolvida unicamente na borda norte da Bacia de Taubaté;

e) fácies de arenitos grossos, arcoseanos, conglomeráticos, localizadamente conglomerados polimíticos. Desenvolvemse como camadas tabulares de grande persistência lateral, espessuras decimétrica a métrica e base erosiva. Apresentam gradação normal de arenitos grossos com seixos de argila na base, até arenitos finos quartzosos, com laminações cavalgantes (climbing ripples); para o topo ocorrem siltitos bioturbados e argilitos com gretas de contração. Estes sedimentos intercalam-se nos argilitos verdes maciços na porção central da Bacia de Taubaté. 
Riccomini (1989) atribuiu ao aumento da profundidade da lâmina de água do lago a passagem sucessiva de dolomitos para argilitos verdes e folhelhos pirobetuminosos. Dessa forma, os dolomitos representam os períodos de maior salinidade do lago. A diminuição na concentração de sais permitiu a decantação por floculação dos argilitos verdes, os quais gradam para os folhelhos pirobetuminosos, com restos de peixes e plantas.

Os arenitos com estratificações cruzadas sigmoidais, presentes na borda norte da Bacia de Taubaté, marcam a chegada de leques aluviais diretamente no lago, formando depósitos tipo leque deltaico. $\mathrm{O}$ fato desta fácies estar bem caracterizada em posição estratigráfica aparentemente de topo em relação ao sistema lacustre, sugere que o delta estava colmatando o lago.

Riccomini (1989) apontou, para os arenitos grossos da porção central da Bacia de Taubaté, uma origem ligada a processos tipo sheet-flood, ocasionados por enchentes esporádicas, depositando corpos de inunditos nas bordas do lago.

A Formação Tremembé apresenta rico conteúdo fossilífero, existindo referências a restos de folhas e troncos de angiospermas, espículas de esponjas, tubos de vermes, gastrópodes, ostracodes, crustáceos, insetos (lepidóptera), peixes, aves, répteis (crocodilianos e quelônios) e mamíferos (quirópteros, taxodontídeos, roedores) (Mezzalira 1989). O conteúdo polínico de amostras de folhelhos pirobetuminosos da Formação Tremembé, atravessados pela sondagem de $n^{\circ} 42$ do Conselho Nacional do Petróleo (CNP), levou Lima et al. (1985) a indicarem idade oligocênica para esta unidade.

PROCEDIMENTO EXPERIMENTAL O estudo dos argilominerais esteve baseado na coleta de amostras das diferentes fácies sedimentares da Formação Tremembé e dos depósitos marginais ao sistema lacustre. Procurou-se efetuar a amostragem em perfis onde pôde ser estabelecida a relação entre as fácies, de modo a se verificar as influências dos processos ligados à dinâmica sedimentar na composição dos argilominerais, bem como dos processos diagenéticos e/ou intempéricos em sua génese.

A caracterização mineralógica qualitativa dos argilominerais foi realizada via difração de raios X (DRX), a partir de amostras totais e das frações menores do que $64 \mu \mathrm{m}$, utilizando-se o difratômetro modelo $\mathrm{HGZ} / 4 \mathrm{~B}$, produzido pela Alemanha Oriental, instalado no Instituto de Química da Universidade Estadual Paulista (IQ-UNESP), Campus de Araraquara, e operando com $36 \mathrm{kV}, 20 \mathrm{~mA}$, radiação $\mathrm{CuK \alpha}$, filtro de Ni e velocidade do goniómetro de $2^{\circ} 2 \theta / \mathrm{min}$. Amostra da fração menor do que 2 um de argilito da Formação Tremembé foi analisada no difratômetro VEB Cari Zeiss JENA do Departamento de Mineralogia e Petrologia do Instituto de Geociências da Universidade de São Paulo (DMP/IG-USP), operando com $40 \mathrm{kV}, 20 \mathrm{~mA}$, radiação $\mathrm{CuK} \alpha$, filtro de $\mathrm{Ni}$ e velocidade do goniómetro de $2^{\circ} 2 \theta / \mathrm{min}$.

Para todas as amostras totais e de frações menores foram obtidos difratogramas rotineiros, de 3 a $65^{\circ} 2 \theta$, sem tratamento prévio. $\mathrm{Na}$ amostra da fração $<2 \mu \mathrm{m}$ foram ainda empregados tratamentos específicos para o estudo dos argilominerais (e.g. Grim 1953, Brindley \& Brown 1980), como aquecimento a $500^{\circ} \mathrm{C}$ por 5 horas e solvatação com etilenoglicol por cerca de 17 horas (Thiry 1974). Estas análises possibilitaram o reconhecimento de diversos grupos de argilominerais nas diferentes fácies sedimentares amostradas e, em algumas delas, o detalhamento a nível de espécies minerais.

Microscopia eletrônica de varredura (MEV) foi utilizada para a visualização das formas, dimensões, texturas e, principalmente, das relações dos argilominerais com outras partículas dos sedimentos. Os dados obtidos, a partir dos equipamen- tos JEOL-JSM-P15 e JEOL-JSM-T330A do IQ-UNESP, Campus de Araraquara, forneceram indicações genéticas dos argilominerais, possibilitando sua classificação em detríticos ou diagenéticos através da comparação das morfologias e texturas imageadas com aquelas já disponíveis na literatura (e.g. Welton 1984), e permitiram inferências em termos paleoclimáticos e paleoambientais.

RESULTADOS Os argilominerais identificados, tanto nos sedimentos lacustres da Formação Tremembé quanto nos depósitos marginais da Formação Resende, correspondem principalmente aos grupos da esmectita e da caulinita, e subordinadamente da mica e clorita. As morfologias e formas de ocorrência destes minerais são descritas em relação às diferentes fácies sedimentares e unidades estratigráficas em que foram constatadas suas presenças. De modo a ilustrar esta distribuição de fácies e demonstrar a sua coexistência lateral foram elaborados mapas paleogeográficos de alguns intervalos estratigráficos na porção central da Bacia de Taubaté, a exemplo daquele da figura 4. Na confecção destes mapas foram empregados os dados de poços perfurados pelo CNP (CNP 1951).

Contexto do paleolago Tremembé Os sedimentos lacustres da Formação Tremembé, representados por argilitos verdes maciços intercalados a níveis de folhelhos papiráceos (Figs. 4, 5A), são compostos essencialmente por esmectita, a qual se associam, de forma subordinada, mica e caulinita, além de quartzo, feldspato e calcita.

Em difratogramas de raios $\mathrm{X}$ de amostras da fração $<64 \mu \mathrm{m}$ destes argilitos verdes (Fig. 5B-2), sem tratamento prévio (amostra natural), a esmectita apresenta-se com reflexão basal 001 de $17 \AA$, de alta intensidade e forma larga. Em difrato-

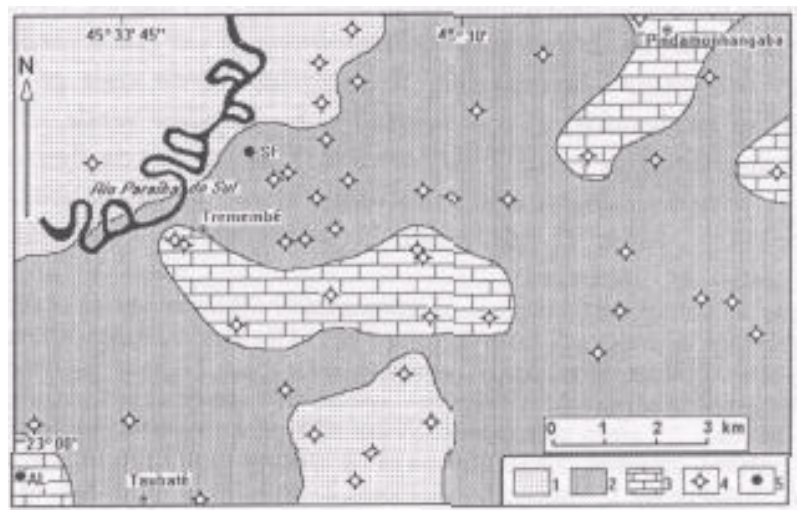

Figura 4 - Mapa paleogeográfico da porção central da Bacia de Taubaté mostrando a extensão máxima dos dolomitos em relação aos argilitos lacustres e o aporte dos leques aluviais da Formação Resende, durante a sedimentação da Formação Tremembé. 1) leques aluviais lamíticos; 2) argilitos verdes lacustres; 3) dolomitos; 4) poços perfurados pelo Conselho Nacional do Petróleo (CNP); 5) principais exposições do sistema lacustre da Formação Tremembé (SF - extração Santa Fé; $A L$ - extração Aligra).

Figure 4 - Paleogeographic map of the central part of the Taubaté Basin showing the maximun extent of dolomites and alluvial fans into the basin during the deposition of the green clays of the Tremembé Formation. 1) alluvial fans; 2) green lacustrine clays; 3) dolomites; 4) wells drilled by the Conselho Nacional do Petróleo (CNP); 5) main outcrops of the lacustrine sediments of the Tremembé Formation (SF - Santa Fé and AL - Aligra clay mines). 

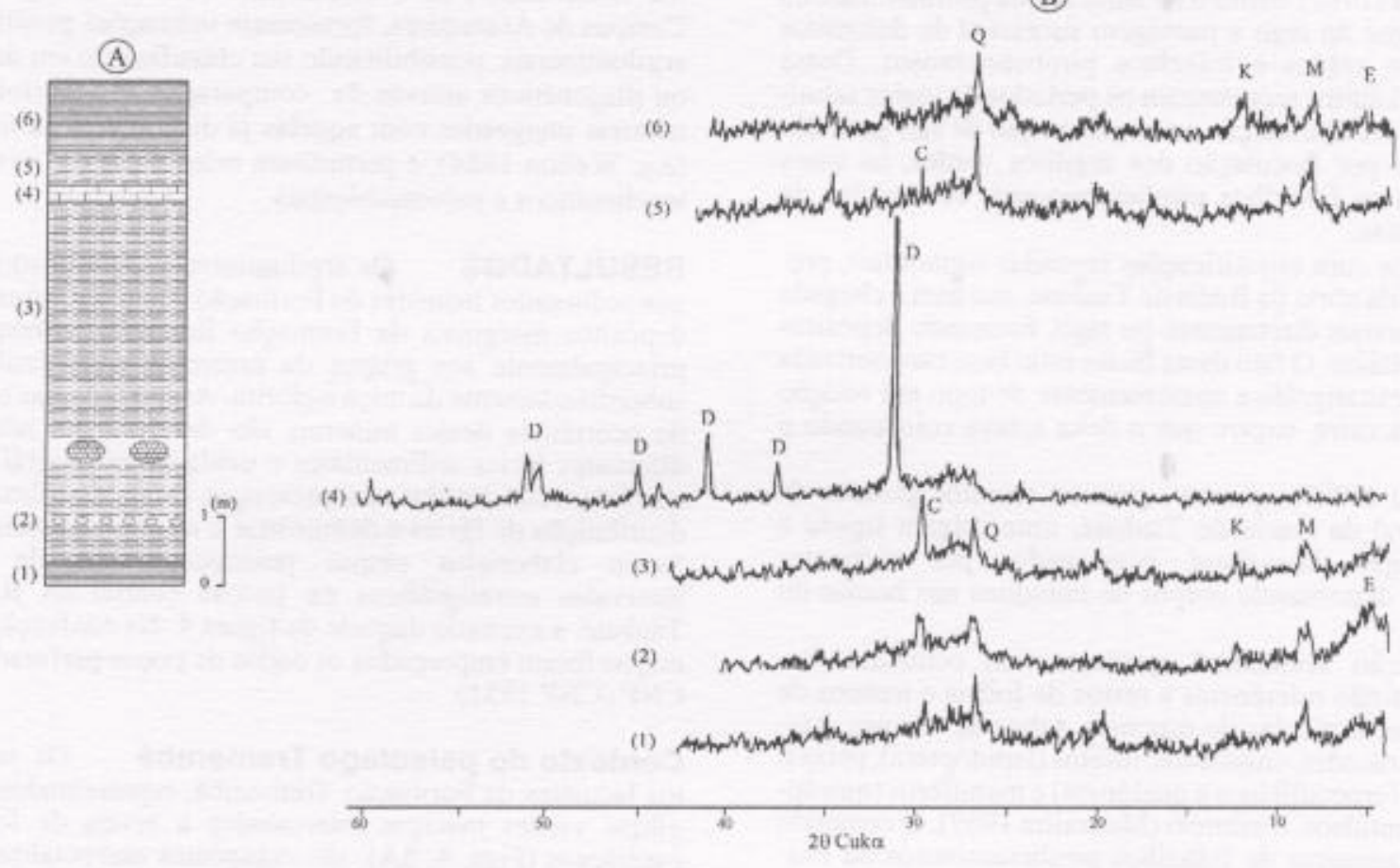

Figura 5 - Formação Tremembé. A) seção colunar representativa das fácies do sistema lacustre, situada na porção central da Bacia de Taubaté (Extração Aligra, Taubaté, SP): 1 e 6 - folhelho papiráceo pirobetuminoso, 2 - argilito verde com carbonato disseminado, 3 - argilito verde com concreções carbonáticas, 4 - dolomito, 5 - argilito verde; B) difratogramas de raios $X$ das amostras dos niveis da figura $A$, na fração $<64 \mu m$ e sem tratamento prévio (Principais picos: $C$ - calcita, $D$ - dolomita, $E$ - esmectita, $K$ - caulinita, $M$ - mica, $Q$ - quartzo).

Figure 5 - Tremembé Formation. A) representative columnar section of the fácies of the lacustrine system in the central part of the Taubaté Basin (Aligra clay mine, Taubaté, SP): 1 and 6 - pyrobituminous shale, 2 - green claystone with disseminated carbonate, 3 - green claystone with carbonate concretions, 4 - dolomite, 5 - green claystone; B) X-ray diffraction diagrams (XRD) of the oriented, untreated $<64 \mu \mathrm{m}$ fraction of the samples from levels indicated in A. (Main peaks: C - calcite, D - dolomite, E - smectite, K - kaolinite, M mica, Q - quartz).

grama de amostra natural da fração $<2 \mu \mathrm{m}$ (Fig. 6), as reflexões basais 001 da mica e subordinadamente da caulinita apresentam altas imensidades, formas bem definidas e estreitas, sendo a esmectita identificada somente após glicolagem, quando sua reflexão basal 001 aumenta de intensidade; após calcinação da amostra, a reflexão basal da esmectita une-se a da mica em d igual a $1 \mathrm{O}, 1 \AA$.

Fotomicrografias de MEV dos argilitos verdes retratam a disposição caótica das esmectitas, que ocorrem como finas placas de bordos arqueados, constituindo uma matriz homogênea (Fig. 7A). A esmectita associa-se ainda clorita, na forma de pequenos "repolhos" (Fig. 7B).

Em difratogramas de raios $\mathrm{X}$ de amostras naturais da fração $<64 \mu \mathrm{m}$ do folhelho papiráceo (Fig. 5B-6), a mica e a caulinita apresentam reflexões basais 001 de $10-10,5 \AA$ e $7,1-7,2 \AA$,

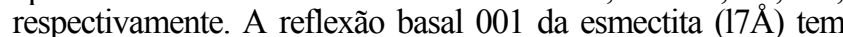
intensidade muito baixa e forma larga. Em fotomicrografia de

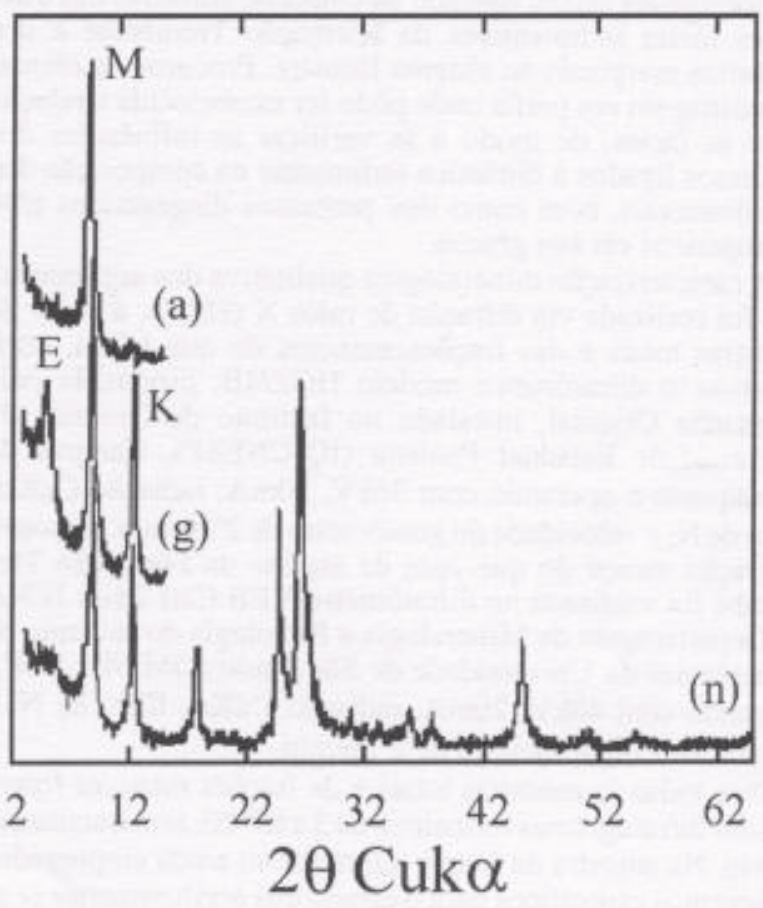

Figura 6 - Difratogramas de raios $X$ de amostra do argilito verde lacustre da Formação Tremembé (nível 2 da figura 5A), na fração $<2 \mu m$ ( $n$ - sem tratamento prévio, $g$ - glicolada, $a$ - aquecida) (Principais picos: $E$ - esmectita, $K$ - caulinita, $M$ - mica).

Figure 6 - XRD diagrams of oriented $<2 \mu \mathrm{m}$ fraction of the green claystone of the Tremembé Formation (level 2, Figure 5A) ( $\mathrm{n}$ - untreated sample, $\mathrm{g}$ glycolated, a - heated). (Main peaks: E - smectite, $\mathrm{K}$ - kaolinite, $\mathrm{M}$ - mica). 

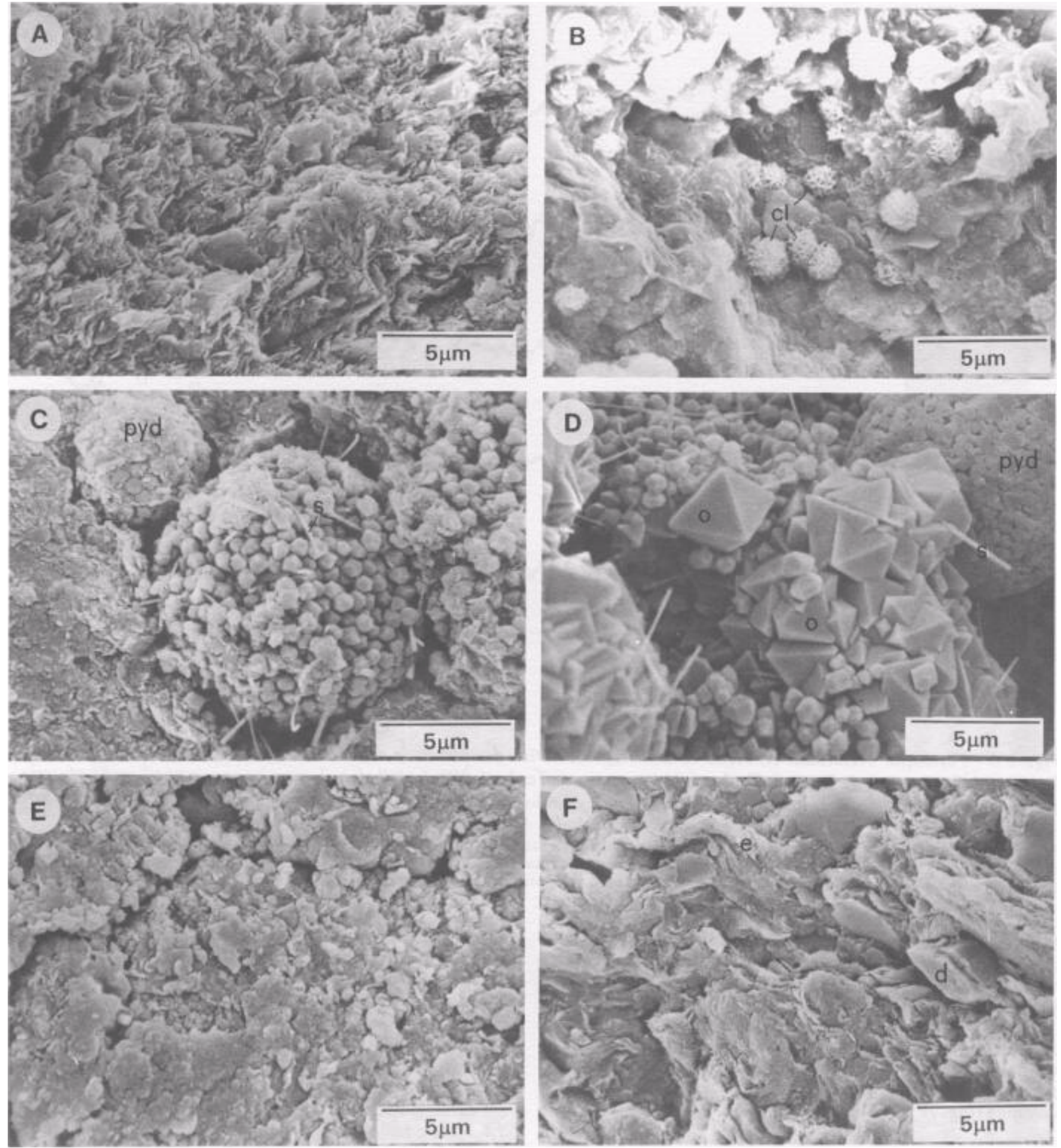

Figura 7 - Fotomicrografias de MEV dos sedimentos lacustres da Formação Tremembé (Extração Aligra, Taubaté, SP). A) esmectita em placas da fácies de argilitos verdes; B) clorita (d) sob a forma de pequenos repolhos salpicados em esmectita da fácies de argilitos verdes; C) pintas framboidais (pyd) com sulfato secundário (s), provavelmente halotriquita, da fácies de folhelhos pirobetuminosos; D) pirita framboidal (pyd), halotriquita (s) e agregados de cristais octaédricos (o) de pirita, da fácies de folhelhos pirobetuminosos; E) caulinita em pequenos flocos da fácies de folhelhos; F) esmectita detritica (e) e dolomita (d), da fácies de argilitos verdes.

Figure 7 - Scanning electron photomicrographs (SEM) of lacustrine sediments of the Tremembé Formation (Aligra clay mine, Taubaté, SP). A) compact aggregates of slighty crenulated to flaky smectitic clay of the green claystone facies; B) chlorite (cl) arranged in a rosette pattern upon the smectite matrix; C) pyrite framboids (pyd) associated with secondary sulphate (s), probable halotrichite in the pyrobituminous shale facies; D) pyrite framboids (pyd), halotrichite (s) and pyrite octahedra (o) in the pyrobituminous shale facies; E) massive aggregates of flaky kaolinite in the shale facies; F) detrital smectite (e) and dolomite (d) of the green claystone facies. 


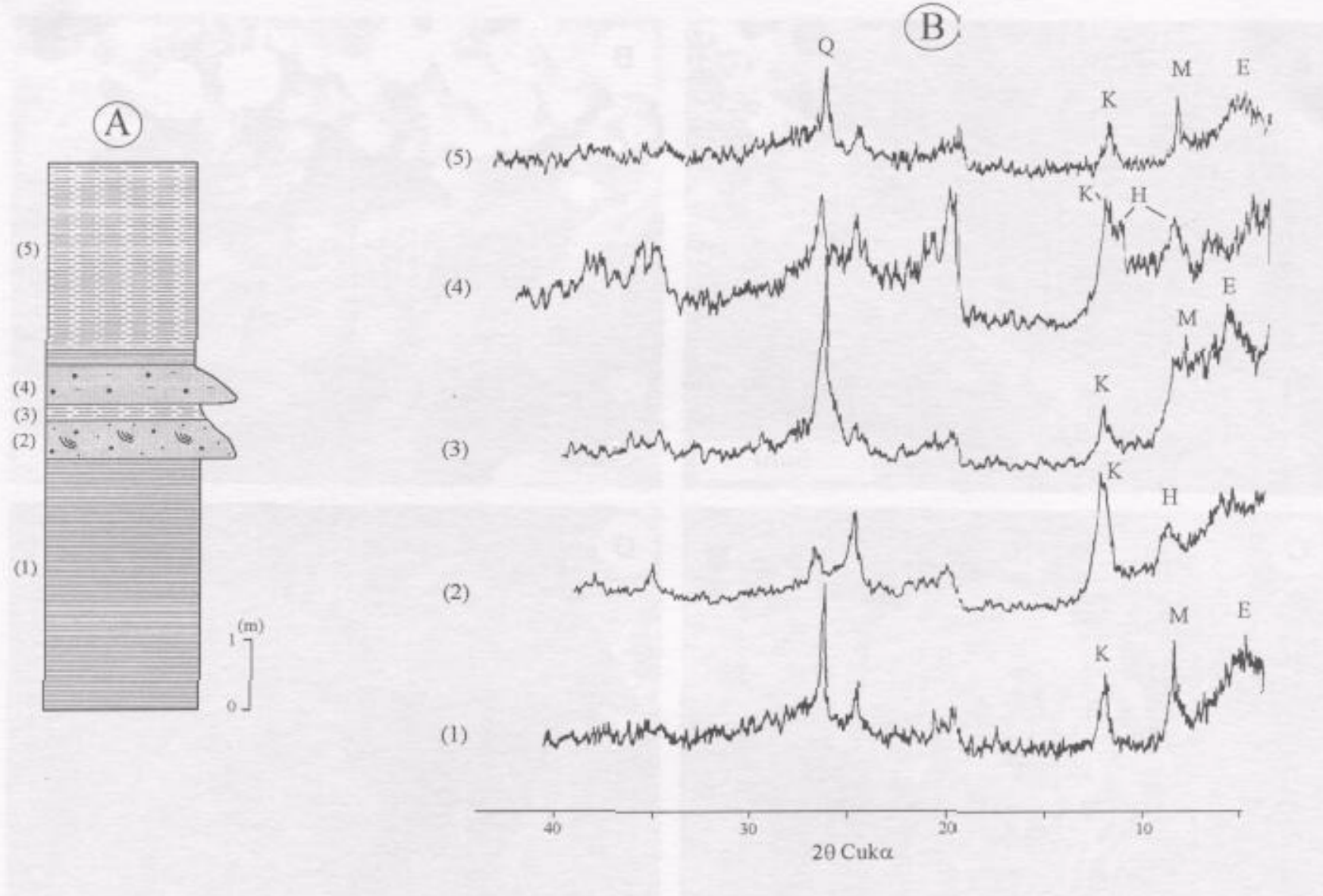

Figura 8 - Formação Tremembé. A) seção colunar representativa das fácies de deltas lacustres intercaladas aos sedimentos lacustres da borda norte da Bacia de Taubaté (16 km a oeste de Taubaté, SP): $J$-folhelho, 2 - arenito com estratificação cruzada, 3 e 5 argilito verde, 4 - arenito maciço; B) difratogramas de raios $X$ de amostras dos niveis da figura A, nafração $<64 \mu m$ sem tratamento prévio (Principais picos: $E$ - esmectita, $K$ - caulinita, $M$ - mica, $Q$ - quartzo).

Figure 8 - Tremembé Formation. A) representative columnar section of the lacustrine delta facies interlayered with lacustrine sediments along the northern border of the Taubaté Basin (16 km W of Taubaté, SP): 1 - shale, 2 - cross-stratified sandstone, 3 and 5 - green claystone, 4 - massive sandstone; B) XRD diagrams of the oriented, untreated $<64 \mu \mathrm{m}$ fractions of samples from levels indicated in A. (Main peaks: E - smectite, $\mathrm{K}$ - kaolinite, M - mica, Q - quartz).

MEV deste sedimento observa-se que piritas framboidais e octaédricas (Figs. 7C, D) encontram-se associadas à esmectita e a caulinita ocorre como placas arredondadas de granulação grossa (Fig. 7E).

No sistema lacustre Tremembé, os carbonatos ocorrem como dolomita em bancos de espessura decimétrica (Figs.5A$4,5 \mathrm{~B}-4)$, ou como minerais disseminados nos argilitos verdes esmectíticos, podendo ser, neste caso, calcita (Fig. 5B-5) ou dolomita (Fig. 7F).

Contexto de deltas lacustres No contexto das fácies de borda do paleolago Tremembé (Fig. 4) é possível notar, ainda atualmente, um contraste marcante entre a mineralogia dos argilominerais dos pacotes arenosos deltáicos e aqueles dos níveis de argilitos e folhelhos lacustres (Figs. 8A, 8B).

Em difratogramas de raios $\mathrm{X}$ de amostras da fração $<64 \mu \mathrm{m}$ dos sedimentos lacustres, sem tratamento prévio, observa-se a preservação da mineralogia, com esmectita em reflexões basais 001 de 15 a $18 \AA$, de média a alta intensidades e bem definidas (Figs. 8B-1, 8B-3, 8B-5), associada a mica (10$10,7 \AA)$ e caulinita $(7,1-7,2 \AA)$. Em fotomicrografias de MEV da fácies de argilitos verdes, depositados nas bordas do lago, nota-se que na matriz esmectítica estão disseminadas placas hexagonais de mica (Fig. 9A), associadas a clorita, e caulinitas de bordas irregulares e formas arredondadas (Fig. 9B).

Os sedimentos arenosos, originados em deltas lacustres, distinguem-se por apresentar argilominerais do grupo da caulinita melhor caracterizados em DRX, os quais sobressaem-se com reflexões basais de maior intensidade em relação à esmectita. Nestas fácies arenosas podem ser identificadas, em difratogramas de amostras da fração $<64 \mu \mathrm{m}$, caulinita com $7,1-7,2 \AA$ e halloysita $10 \AA$, as quais apresentam-se com reflexões basais largas de média a alta intensidade (Figs. 8B-2, 8B-4). Em MEV observa-se que a caulinita apresenta-se como placas grossas arredondadas ou em textura vermiforme bem desenvolvida (Fig. 9C), e a halloysita 10Å é tubular (Fig. 9D). No difratograma de raios $\mathrm{X}$ da figura $8 \mathrm{~B}-4$, o pico de $7,4 \AA$ corresponde à halloysita desidratada.

Contexto de leques aluviais distais Os depósitos distais da Formação Resende, predominantemente argilosos e localizadamente com calcretes (fig. 4), são caracterizados por conter dois tipos texturais de esmectitas: um deles como finas placas de bordos arqueados e outro como flocos lembrando "pés-de-alface" (Riccomini 1989). 

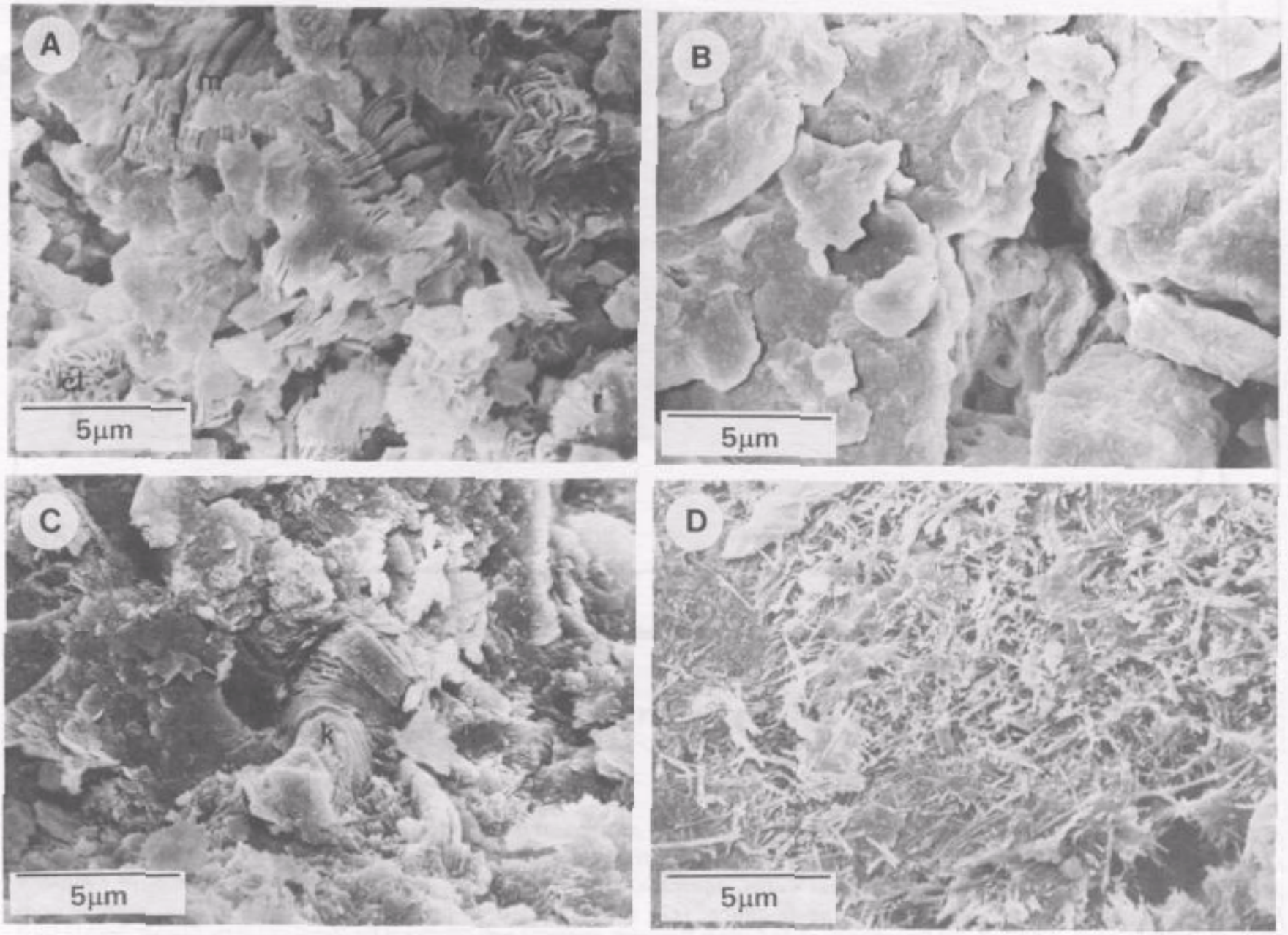

Figura 9 - Fotomicrografias de MEV dos sedimentos de deltas lacustres da Formação Tremembé (10 km a noroeste de Taubaté, SP). A) mica (m) associada a clorita (cl) da fácies de argilitos verdes lacustres; B) caulinita em placas da fácies de argilitos verdes; C) caulinita em textura vermiforme (k) da fácies de arenitos de deltas lacustres; D) halloysita tubular da fácies de arenitos de deltas lacustres.

Figure 9 - SEM photomicrographs of lacustrine delta sediments of the Tremembé Formation (10 km NW of Taubaté, SP). A) mica (m) associated with chlorite (cl) of the green claystone facies; B) rounded plates of kaolinite of the green claystone facies; C) worm-like kaolinite (k) of sandstones from the delta facies; D) tubes of halloysite of sandstones of the lacustrine delta facies.

Para melhor caracterização dos argilominerais presentes nesta fácies foram analisadas amostras provenientes das bacias de Taubaté, Resende e São Paulo.

Em fotomicrografia de MEV (Fig, 10) é possível notar que as esmectitas finas de bordos arqueados são predominantes e, que os pequenos flocos de esmectita com arranjo em "pé-dealface" estão intimamente associados à calcita, esta presente como pequenos romboedros intersticiais na matriz argilosa (Figs. 10, 11,12, 13).

Em difratogramas de raios $\mathrm{X}$ de amostras totais dos lamitos distais da Formação Resende (Figs. 10,11,12,13), a esmectita apresenta reflexões basais 001 entre 14 e $17 \AA$, de baixa intensidade. Associadas às esmectitas ocorrem caulinitas com reflexões basais 001 de 7,1-7,2 $\AA$ também de baixa intensidade. A presença de esmectita é muito evidente em difrato- gramas de raios $\mathrm{X}$ de amostras da fração $<2 \mu \mathrm{m}$, sem tratamento prévio, onde apresenta-se com picos basais em torno de $16 \AA$, de alta intensidade, estreitos e bem definidos. Nestes difratogramas, a caulinita $(7,2 \AA)$ aumenta a intensidade de sua reflexão basal 001 . A illita, não identificada previamente nos difratogramas de raios $\mathrm{X}$ das amostras totais, apresenta-se, após calcinação das amostras da fração $<2 \mu \mathrm{m}$, com espaçamentos basais em torno de 9,9-10, $1 \AA$ em reflexões 001 de baixa a média intensidade.

DISCUSSÕES E INTERPRETAÇÕES Minerais detríticos Os argilominerais detríticos dos sedimentos das formações Resende e Tremembé são representados principalmente pelas esmectitas de bordos arqueados (Riccomini 1989). 


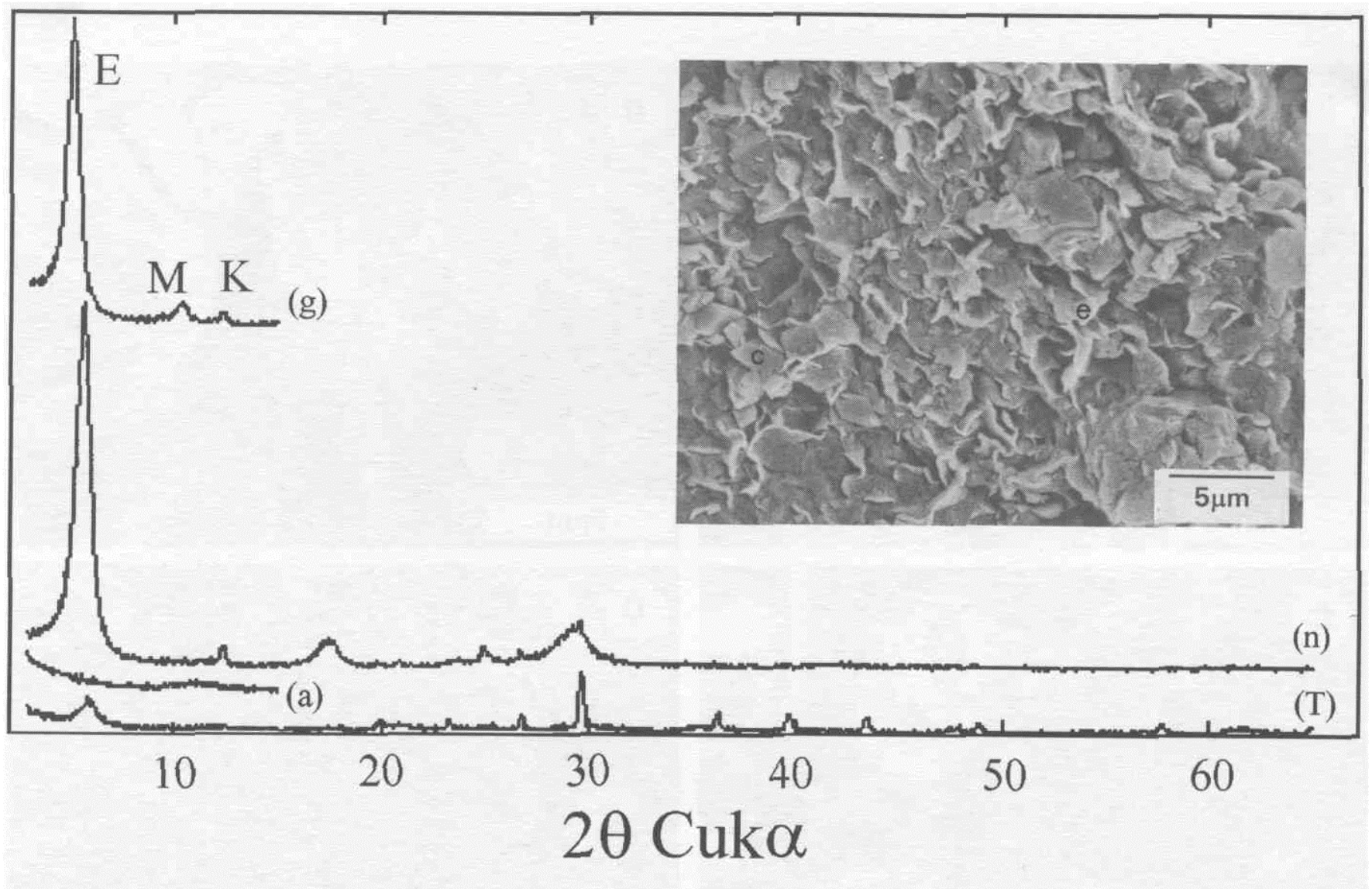

Figura 10 - Sedimentos lamíticos distais da Formação Resende, associados a calcretes, na porção central da Bacia de Resende $(2 \mathrm{~km}$ a leste de Resende, RJ). Difratogramas de raios $X$ (T-amostra total sem tratamento prévio, $n$-fração $<2 \mu$ m, sem tratamento

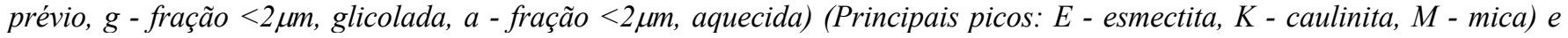
fotomicrografia he MEV com esmectita hpo "pé-de-alface" (e) e calcita (c).

Figure 10 - XRD diagrams of distal alluvial fan sediments of the Resende Formation, associated with calcretes in the central part of the Resende Basin (2 km E of Resende, RJ). (T - total untreated sample, $\mathrm{n}$ - untreated $<2 \mu \mathrm{m}$ fraction, $\mathrm{g}$ - glycolated $<2 \mu \mathrm{m}$ fraction, a - heated $<2 \mathrm{~nm}$ fraction). (Main peaks: E - smectite, $\mathrm{K}$ kaolinite, M - mica). SEM photomicrography showing webby or highly-crenulated smectite (e) and calcite (c).

Suguio (1969) relacionou a gênese dos sedimentos esmectíticos do Grupo Taubaté à alteração das biotitas das rochas pré-cambrianas do embasamento. A coexistência de esmectitas e caulinitas nos sedimentos foi explicada pelo autor como resultante da alteração coetânea de biotitas para esmectitas e de feldspatos para caulinitas. Resguardando-se da afirmação de clima semi-árido, Suguio $(1969$, p.65) atribuiu a predominância de esmectita ou caulinita nos sedimentos às condições locais "que prevaleciam no ambiente para a formação de um ou outro mineral".

Riccomini (1989) sugeriu a formação de caulinitas em clima úmido pretérito e posterior alteração para esmectitas em clima semi-árido. Na literatura são raras as referências à passagem de caulinitas para esmectitas em condições supérgenas, sendo clássico o trabalho de Bocquier et al. (1970), no qual os autores descreveram este processo como consequência da progressiva saturação iônica de solos, originando um ambiente confinado e alcalino onde se forma a esmectita. Para alguns autores (e.g. Chamley 1989) esta alteração de caulinitas para esmectitas possui um significado paleoclimático indicativo de aumento na aridez.

Riccomini et al. (1996), seguindo seus estudos sobre a evolução paleoclimática e paleogeográfica do sudeste do Brasil, apontam para estas esmectitas do Grupo Taubaté uma origem a partir das rochas pré-cambrianas do embasamento e condicionada essencialmente pelos fatores climáticos semiáridos da época, os quais minimizaram a influência litológica das áreas-fonte, cujos produtos de alteração foram homogeneizados em escala regional, gerando espessos paleossolos durante o Eoceno Inferior a Médio. A partir destes paleossolos foram então gerados os pacotes lamíticos da Formação Resende, posteriormente depositados em contexto paleogeográfico acidentado, com forte influência tectônica, no Eoceno Superior-Oligoceno.

Em linhas gerais, esta tendência à aridez climática verificada no intervalo entre o Eoceno Inferior a Médio do sudeste do Brasil, conforme sugerido pelas esmectitas detríticas, está de acordo com a tendência paleoclimática global (e.g. Frakes et al, 1994), estabelecida com base em dados geológicos e paleoceanográficos, em que o período de 105 a $55 \mathrm{Ma}$ (Cretáceo Médio a Eoceno Inferior) é reconhecido como um dos mais quentes no Fanerozóico tardio.

A manutenção de condições semi-áridas ainda durante o Eoceno Superior-Oligoceno no sudeste do Brasil é um aspecto climático traduzido nos sistemas deposicionais das unidades (leques aluviais associados a rios entrelaçados e lago do tipo playa-lake) e pela presença de calcretes pedogenéticos, tipo 


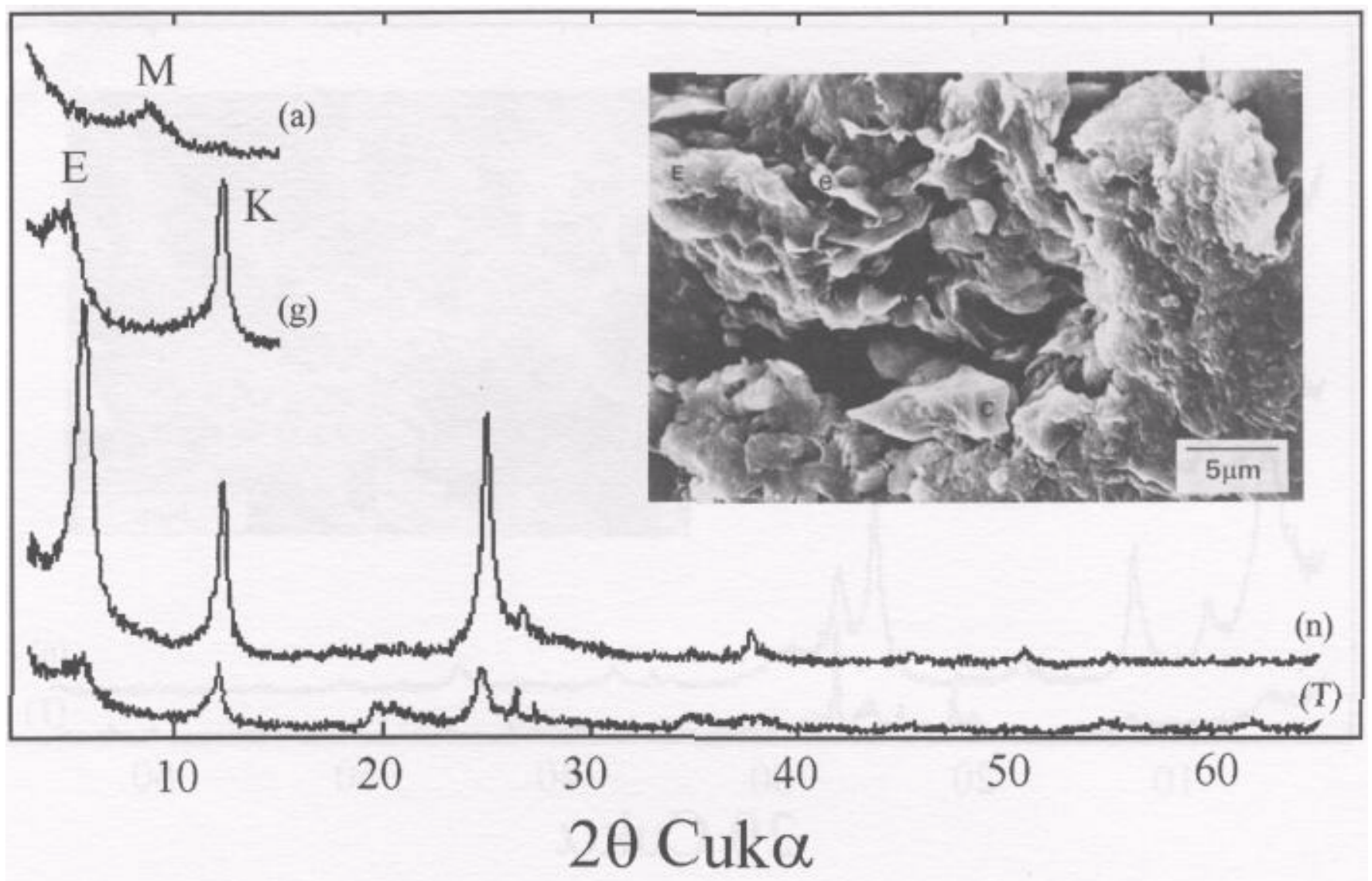

Figura 11 - Sedimentos lamíticos distais da Formação Resende, associados a calcretes, na porção central da Bacia de Resende (2,2 km a ENE de Resende, RJ). Difratogramas de raios X (T-amostra total sem tratamento prévio, $n$-fração $<2 \mu m$, sem tratamento

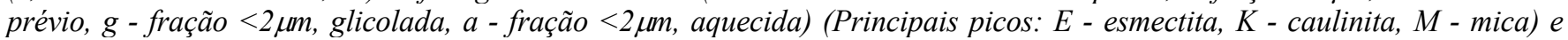
fotomicrografia de MEV com esmectita tipo "pé-de-alface" (e) e detrítica (E), além de calcita (c).

Figure 11 - XRD diagrams of distal alluvial fan sediments of the Resende Formation, associated with calcretes in the central part of the Resende Basin (2.2 km ENE of Resende, RJ). ( $\mathrm{T}$ - total untreated sample, $\mathrm{n}$ - untreated $<2 \mu \mathrm{m}$ fraction, $\mathrm{g}$ - glycolated $<2 \mu \mathrm{m}$ fraction, a - heated $<2 \mu \mathrm{m}$ fraction). (Main peaks: $\mathrm{E}$ - smectite, $\mathrm{K}$ - kaolinite, M - mica). SEM photomicrography showing webby or highly-crenulated (e) and detrital (E) smectite, and calcite (c).

caliche (Coimbra \& Riccomini 1985), intercalados aos pacotes lamíticos distais da Formação Resende.

O caráter seco do clima à época de sedimentação das formações Resende e Tremembé foi ainda apontado pelos estudos palinológicos realizados em sedimentos de topo dessas unidades, respectivamente por Lima \& Amador (1985) e Lima et al. (1985).

As camadas decimétricas de dolomitos intercaladas aos argilitos verdes lacustres (Figs. 4, 5A) foram atribuídas por Riccomini (1989) às fases de hipersalinidade do lago, em águas rasas. De fato, a presença exclusiva de dolomita em um destes níveis, como indicam os estudos por DRX, sugere uma cristalização in situ para a este mineral, provavelmente em épocas de secas, sem fornecimento de detritos ao ambiente lacustre.

A contribuição de outros argilominerais detríticos na constituição mineralógica dos sedimentos das formações Resende e Tremembé é assinalada pela presença de mica e caulinita em placas grandes e arredondadas. Estes minerais tornam-se mais abundantes para o topo do Grupo Taubaté, na Formação São Paulo, sendo então considerados indicativos da passagem para climas úmidos e quentes à época de deposição desta unidade no Oligoceno Superior, em concordância com o sistema fluvial meandrante verificado (Riccomini 1989).
Pomerol \& Premoli-Silva (1986) afirmam que o limite Eoceno-Oligoceno foi marcado por várias alternâncias paleoclimáticas, entre fases de pequenas durações, as quais levaram a uma mudança global gradual, que culminou com um evento generalizado de resfriamento. Nesse sentido, são reconhecidos, ainda que preliminarmente, como registros da graduação do cenário climático eocênico-oligocênico no sudeste do Brasil, a interdigitação das formações Resende e São Paulo e a concentração de caulinitas detríticas somente no topo desta última unidade.

\section{Diagênese A diagênese promoveu a formação de} esmectita em flocos, clorita, illita e caulinita vermiforme.

As esmectitas diagenéticas cresceram intimamente associadas aos níveis de calcrete ou aos carbonatos disseminados na matriz dos sedimentos das formações Resende e Tremembé. Riccomini et al. (1994) vincularam a origem destas esmectitas autigênicas à liberação da sílica pelo ataque superficial de grãos de quartzo por águas carbonatadas, reagindo com a esmectita detrítica e formando arranjo neoformado, com posterior precipitação de calcita cristalina intersticial.

As cloritas desenvolveram-se nos argilitos verdes da Formação Tremembé, associadas à esmectita e sulfetos. Segundo 


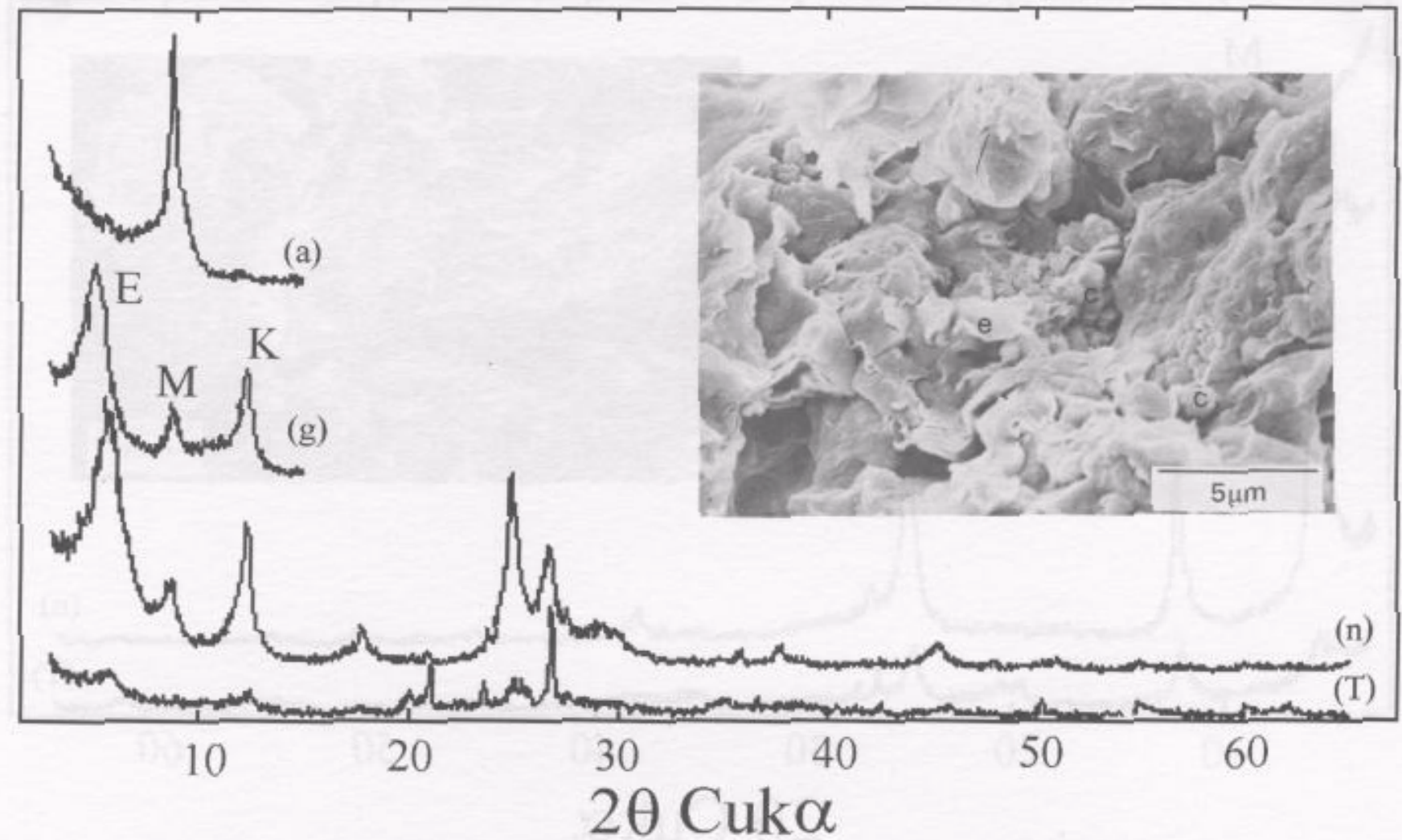

Figura 12 - Sedimentos lamíticos distais da Formação Resende, associados a calcretes, no extremo sudoeste da Bacia de Taubaté. Difratogramas de raios $X(T$ - amostra total sem tratamento prévio, $n$-fração $<2 \mu m$, sem tratamento prévio, $g-f r a c ̧ a ̃ o ~<2 \mu m$, glicolada, a -fração $2 \mu \mathrm{m}$, aquecida) (Principais picos: $E$ - esmectita, $K$ - caulinita, $M$ - mica) e fotomicro grafia de MEV com esmectita tipo "pé-de-alface" (e) e calcita (c).

Figure 12 - XRD diagrams of distal alluvial fan sediments of the Resende Formation, associated with calcretes in the southwestern extremity of the Taubaté Basin. ( $\mathrm{T}$ - total untreated sample, $\mathrm{n}$ - untreated $<2 \mu \mathrm{m}$ fraction, $\mathrm{g}$ - glycolated $<2 \mu \mathrm{m}$ fraction, a - heated $<2 \mathrm{pm}$ fraction). (Main peaks: $\mathrm{E}$ - smectite, $\mathrm{K}$ - kaolinite, $\mathrm{M}$ mica). SEM photomicrography showing webby or highly-crenulated smectite (e) and calcite (c).

Riccomini (1989) as cloritas estariam relacionadas à maior concentração em magnésio dos argilitos verdes maciços da Formação Tremembé, os quais contêm ainda dolomita. Illitas diagenéticas foram reconhecidas por Riccomini (1989) nos sedimentos lacustres da Formação Tremembé; no entanto, os processos diagenéticos envolvidos na sua formação ainda não estão esclarecidos e serão motivo de estudos futuros.

Argilominerais do grupo da caulinita também são neoformados. Riccomini (1989) atribuiu origem diagenética para as halloysitas presentes nos arenitos deltaicos da Formação Tremembé, as quais proviriam da decomposição de feldspatos abundantes nessa fácies. Sant'Anna \& Valarelli (1996) apresentam a hipótese alternativa de origem autigênica, contemporânea à sedimentação destes arenitos na borda do lago, e sugerem uma cristalização a partir da alteração dos feldspatos, através da hidrólise por águas ácidas, provavelmente das chuvas, acompanhada da carreação das bases para as águas alcalinas do lago Tremembé, levando à formação de um gel enriquecido em Si e Al. As halloysitas seriam então produtos autigênicos (eodiagenéticos), indicativos de sazonalidade pluviométrica vigente à época da sedimentação.

As caulinitas vermiformes são atribuídas à alteração dos feldspatos pela percolação de águas ácidas (Riccomini 1989), provavelmente em estágios diagenéticos mais avançados e sem a influência do meio deposicional.

CONCLUSÕES Os argilominerais detríticos mais abundante nos sedimentos lacustres da Formação Tremembé e nas fácies distais da Formação Resende pertencem ao grupo das esmectitas. A presença desses argilominerais é indicativa das condições paleoclimáticas com tendência à aridez, vigentes durante a época de sua geração, provavelmente no Eoceno Inferior a Médio. As rochas pré-cambrianas do embasamento contribuiram em grande escala como área-fonte dos paleossolos esmectíticos, permanecendo ainda obscuros os processos genéticos envolvidos na formação destas esmectitas, os quais somente poderão ser elucidados através de estudos mineralógicos e geoquímicos.

A sedimentação destas unidades, no Eoceno Superior a Oligoceno Inferior, ocorreu ainda sob clima semi-árido, o qual propiciou o desenvolvimento de ambientes sedimentares característicos e a formação de calcretes pedogenéticos. A cristalização de halloysitas, nas fácies sedimentares de borda do paleolago Tremembé, marca a sazonalidade pluviométrica então atuante. 


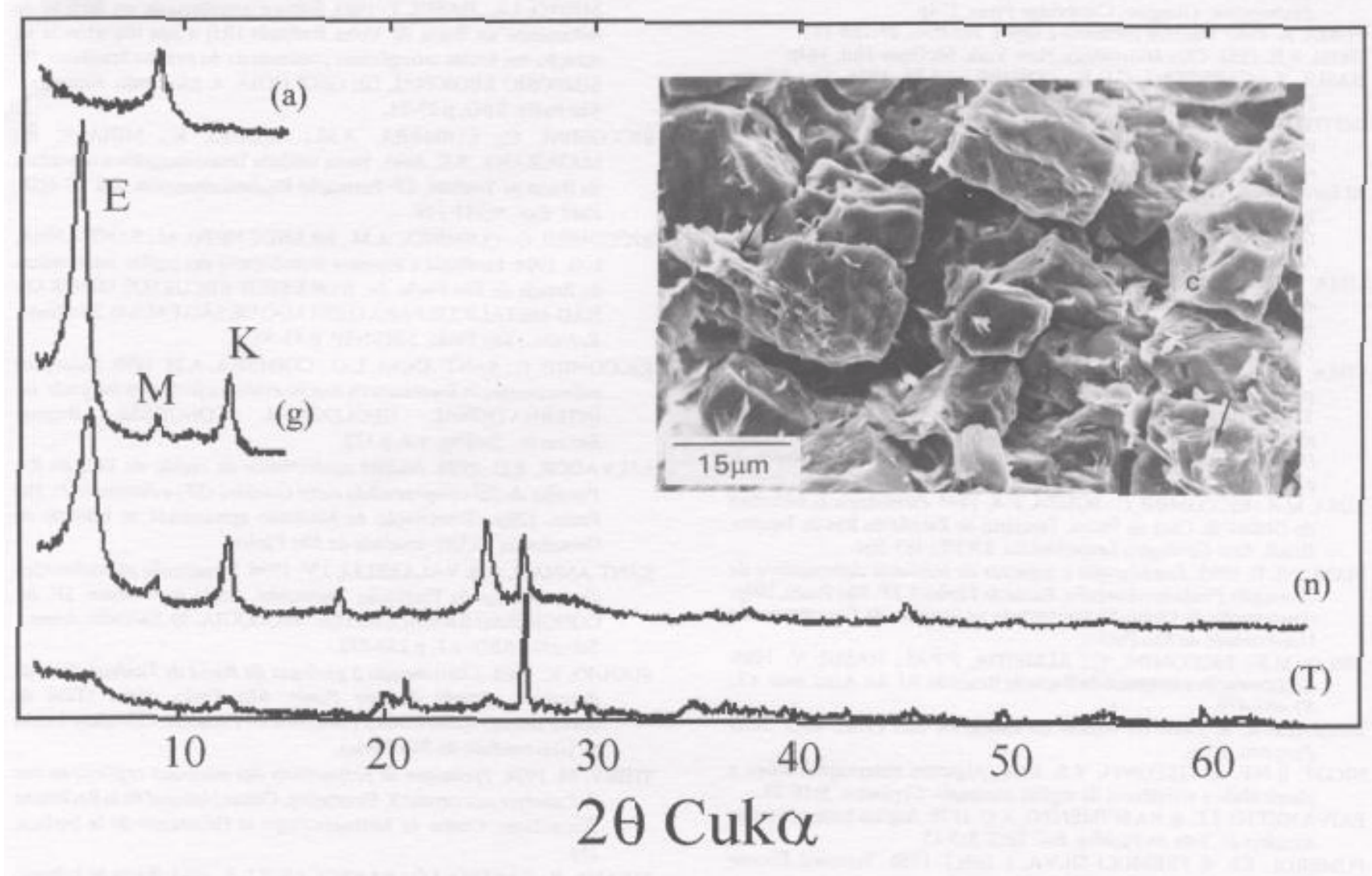

Figura 13 - Sedimentos lamíticos distais da Formação Resende, associados a calcretes, na parte central da borda norte da Bacia de São Paulo. Difratogramas de raios X (T - amostra total sem tratamento prévio, $n$-fração $<2 \mu m$, sem tratamento prévio, $g$ fração $<2 \mu \mathrm{m}$, glicolada, a -fração $<2 \mu \mathrm{m}$, aquecida) (Principais picos: E - esmectita, $K$ - caulinita, $M$ - mica) e fotomicrografia de MEV com esmectita tipo "pé-de-alface" (setas) e calcita (c).

Figure 13 - XRD diagrams of distal alluvial fan sediments of the Resende Formation, associated with calcretes, central part of the northern border of the São Paulo Basin. ( $\mathrm{T}$ - total untreated sample, $\mathrm{n}$ - untreated $<2 \mu \mathrm{m}$ fraction, $\mathrm{g}$ - glycolated $<2 \mu \mathrm{m}$ fraction, a - heated $<2 \mu \mathrm{m}$ fraction). (Main peaks: $\mathrm{E}$ - smectite, $\mathrm{K}$ - kaolinite, $\mathrm{M}$ - mica). SEM photomicrography showing webby or highly-crenulated smectite (arrows) and calcite (c).

O sistema fluvial meandrante da Formação São Paulo, com sedimentos essencialmente cauliníticos, sugere uma significativa mudança climática para tempos provavelmente mais úmidos no Oligoceno Superior.

De modo geral, os argilominerais dos sedimentos paleogênicos da Bacia de Taubaté (RCSB) indicam condições paleoambientais similares à tendência global da época.
Agradecimentos À Fundação de Amparo à Pesquisa do Estado de São Paulo -FAPESP (processos 93/0633-8, 95/3381-5 e 96/0029-1 e ao Conselho Nacional de Desenvolvimento Científico e Tecnológico pelo apoio financeiro e científico; ao Dr. Thomas R. Fairchild e aos revisores da revista pelos oportunos comentários e sugestões.

\section{REFERENCIAS}

ALMEIDA, F.F.M. 1958. O Planalto Paulistano. In: A Cidade de São Paulo. Associação Brasileira de Geógrafos Brasileiros, p. 113-167, São Paulo. ALMEIDA, F.F.M. 1976. The system of continental rifts bordering the Santos Basin, Brazil. An. Acud. brus. CL, 48 (suplemento):15-26.

AMARAL, G.; BUSHEE, J.; CORDANI, U.G.; KAWASHITA, K.; REYNOLDS, J.H. 1967. Potassium-argon ages of alkalines rocks from Southern Brazil. Geoch. Cosmoch. Acta, 31:117-142.

BOCQUIER, G.; PAQUET, H.; MILLOT, G. 1970. Un nouveau type d'accumulation oblique dans les paysages géochimiques: 1'invasion remontante de Ia montmorillonite. C. R. Acad. Sc. Paris, Tomo 270 , Serie D, 3(19):460-463.

BRANDT NETO, M.; RICCOMINI, C.; COIMBRA, A.M.; MATOS, S.L.F. 1991. Argilominerais da Bacia de Taubaté. Bol. IG-USP. Publicação Especial. 9:111-115.
BRINDLEY G.W. \& BROWN, G. (eds) 1980. Crystal structures of clay minerals and their X-ray identification. London, Mineralogical Socieu. 495p.

CHAMLEY. H 1989. Clay sedimentology. Heidelberg, Springer-Verlag, $623 \mathrm{p}$.

COIMBRA, A.M. \& RICCOMINI, C. 1985. Considerações paleoambientais sobre as ocorrências de caliche nas bacias de Curitiba (PR), Taubaté (SP), Resende (RJ). An. Acad. bras. CL, 57:517-518.

CONSELHO NACIONAL DO PETRÓLEO - CNP. 1951. Xisto Betuminoso. Rio de Janeiro, CNP, Relatório de 1951.

COUTO, C.P. 1953. Une chauvre-souris possible des argiles feuilletes, pleistocene de Tremembé, Etat de São Paulo (Brésil). In: CONGRES INTERNATIONAL DU QUATERNAIRE, 4, Rome-Pisa. Actes.. Rome, 1956, v.1, p.343-347. 
FRAKES, L.A.; FRANGIS, J.E.; SYKTUS, J.I. 1994. Climate modes of the Phaneroz.oic. Glasgow, Cambridge Press, 274p.

FURIA, A. 1940. Material refratário e argila. Bol IGG, 27:163-177.

GRIM, R.E. 1953. Clay Mineralogy. New York, McGraw-Hill, 384p.

HASUI, Y.; CARNEIRO, C.D.R.; COIMBRA, A.M. 1975. The Ribeira Folded Belt. Rev. Bras. Geoc., 5:257-266.

INSTITUTO DE PESQUISAS TECNOLÓGICAS DO ESTADO DE SÃO PAULO S/A - IPT. 1975. Análises mineralógicas da fração argila de rochas de Taubaté. São Paulo, IPT, Relatório 8.126.

KLEIN, V.C. \& VALENCA, J.G. 1984. Estruturas almofadadas em derrame ankaramítico na Bacia de São José de Itaboraí, Rio de Janeiro. In:

CONGRESSO BRASILEIRO DE GEOLOGIA, 33, Rio de Janeiro. Anais... Rio de Jneiro, SBG, v.9, p.4335-4345.

LIMA, M.R. \& AMADOR, E.S. 1985. Análise palinológica de sedimentos da Formação Resende, Terciário do Estado do Rio de Janeiro, Brasil. In: Coletânea de trabalhos paleontológicos, Brasília, DNPM. Série Geologia, 27, Seção Paleontologia e Estratigrafia, 2, p.371-378

LIMA, M.R.; SALARD-CHEBOLDAEFF, M.; SUGUIO, K. 1985. Étude palynologique de Ia Formation Tremembé, Tertiaire du Bassin de Taubaté (État de São Paulo, Brésil), d'après les echantillons du sond.age $\mathrm{n}^{\mathrm{o}} 42$ du CNP. In: Coletânea de trabalhos paleontológicos, Brasília, DNPM. Série Geologia, 27, Seção Paleontologia e Estratigrafia, 2, p.379-393.

LIMA, M.R.; RICCOMINI, C.; SOUZA, P.A. 1994. Palinologia de folhelhos do Gráben de Casa de Pedra, Terciário do Estado do Rio de Janeiro, Brasil. Acta Geológica Leopoldensia, 27(3/2):485-504.

MANCINI, F. 1995. Estratigrafia e aspectos da tectônica defarmadora da Formação Pindamonhangaba, Bacia de Taubaté, SP. São Paulo, 107p. (Dissertação de Mestrado apresentada ao Instituto de Geociências da Universidade de São Paulo).

MELO, M.S.; RICCOMINI, C.; ALMEIDA, F.F.M.; HASUI, Y. 1985. Sedimentação e tectônica da Bacia de Resende, RJ. An. Acad. bras. Ci., 57:467-479.

MEZZALIRA, S. 1989. Os fósseis do Estado de São Paulo. IGG, Série Pesquisa, 155p.

NICOT, B.N.F. \& VISCONTI, Y.S. 1959. Algumas observações sobre a plasticidade e resistência de arguas nacionais. Cerâmica, 5:18-29.

PAIVA NETTO, J.E. \& NASCIMENTO, A.C. 1956. Arguas bentoníticas no terciário do Vale do Paraíba. Bol SBG, 5:5-15.

POMEROL, Ch. \& PREMOLI-SILVA, I. (eds.). 1986. Terminal Eocene events. Developments in paleontology and stratigraphy. Amsterdam, Elsevier, 9, 414p.

RICCOMINI, C. 1989. O Rift Continental do Sudeste do Brasil. São Paulo, 256p. (Tese de doutoramento apresentada ao Instituto de Geociências da Universidade de São Paulo).

RICCOMINI, C. 1995. Tectonismo gerador e deformado $r$ dos depósitos sedimentares pós-gondvânicos da porção centro-oriental do Estado de São Paulo e áreas vizinhas. São Paulo, 1OOp. (Tese de livre-docência apresentada ao Instituto de Geociências da Universidade de São Paulo).

RICCOMINI, C. \& COIMBRA, A.M. 1992. Geologia da bacia sedimentar In: NEGRO JR., A.; FERREIRA, A.A.; ALONSO, U.R.; LUZ, P.A. (eds). 1992. Solos da Cidade de São Paulo. São Paulo, ABMS/ABEF, p.37-94.

RICCOMINI, C. \& RODRIGUES FRANCISCO, B.H. 1992. Idade potássio-argônio do derrame de ankaramito da Bacia de Itaborá, Rio de Janeiro, Brasil: implicações tectônicas. In: CONGRESSO BRASILEIRO DE GEOLOGIA, 37, São Paulo. Boletim de Resumos Expandidos... São Paulo, SBG, v.2, p.469-470.
RICCOMINI, C.; MELO, M.S.; ALMEIDA, F.F.M.; CARNEIRO, C.D.R.; MIOTO, J.A.; HASUI, Y. 1983. Sobre a ocorrência de um derrame de ankaramito na Bacia de Volta Redonda (RJ) e sua importância na datação das bacias tafrogênicas continentais do sudeste brasileiro. In: SIMPÓSIO REGIONAL DE GEOLOGIA, 4, São Paulo. Resumos.. São Paulo, SBG, p.23-24.

RICCOMINI, C.; COIMBRA, A.M.; SUGUIO, K.; MIHÁLY, P.; MATURANA, E.C. 1991. Nova unidade litoestratográfica cenozóica da Bacia de Taubaté, SP: Formação Pindamonhangaba. Bol. IG-USP, Publ Esp., 9:141-149.

RICCOMINI, C.; COIMBRA, A.M.; BRANDT NETO, M.; SANT'ANNA, L.G. 1994. Geologia e aspectos tecnológicos das arguas esmectíticas do Estado de São Paulo. In: WORKSHOP RECURSOS MINERAIS NÃO-METÁLICOS PARA O ESTADO DE SÃO PAULO, São Paulo. Boletim... São Paulo, SBG/NSP, p.43-50.

RICCOMINI, C.; SANTANNA, L.G.; COIMBRA, A.M. 1996. Paleogene paleoclimates in Southeastern Brazil: evidence from clay minerais. In: INTERNATIONAL GEOLOGICAL CONGRESS, Beijing. Abstracts... Beijing, v.2, p. 172.

SALVADOR, E.D. 1994. Análise neotectônica da região do Vale do Rio Paraíba do Sul compreendida entre Cruzeiro (SP) e Itatiaia (RJ). São Paulo, 129p. (Dissertação de Mestrado apresentada ao Instituto de Geociências da Universidade de São Paulo).

SANTANNA, L.G \& VALARELL1, J.V. 1996. Significado paleoclimático das halloisitas da Formação Tremembé, Bacia de Taubaté, SP. In: CONGRESSO BRASILEIRO DE GEOLOGIA, 39, Salvador. Anais.. Salvador, SBG, v.1, p.230-232.

SUGUIO, K. 1969. Contribuição à geologia da Bacia de Taubaté, Vale do Paraiba - Estado de São Paulo. São Paulo, 106p. (Tese de doutoramento apresentada à Faculdade de Filosofia, Ciências e Letras da Universidade de São Paulo).

THIRY, M. 1974. Technique de préparation dês minéraux argileux en vue de l'analyse aux rayons $X$. Strasbourg, Centre National de la Recherche Scientifíque, Centre de Sédimentologie et Géochimie de la Surface, 25p.

TIBANA, P.; CASTRO, J.C.; BARROCAS, S.L.S. 1984. Bacia de Itaboraí. In: CONGRESSO BRASILEIRO DE GEOLOGIA, 33, Rio de Janeiro. Anais... Rio de Janeiro, SBG, v. 12, p.5309-5316.

TURNER, S.; REGELOUS, M.; KELLEY, S.; HAWKESWORTH, C.; MANTOVANI, M. 1994. Magmatism and continental break-up $m$ the South Atlantic: high precision ${ }^{40} \mathrm{Ar}^{39} \mathrm{Ar}$ geochronology. Earth Planet. Sci. Lett., 124:333-348.

WELTON, J.E. 1984. SEM Petrology Atlas. Methods in Exploration Series. Tulsa, AAPG, 237p.

MANUSCRITO A907

Recebido em 10 de fevereiro de 1997

Revisão dos autores em 10 de abril de 1997

Revisão aceita em 15 de abril de 1997 